\title{
Desarrollo territorial rural y estructuras de gobernanza en Brasil
}

\section{Territorial development and new structure of governance in Brazil}

\author{
Antonio César Ortega*
}

\begin{abstract}
In recent years Brazil has implemented rural development policies that have resulted in socio-productive innovation and strategies for territorial development. Examples include Inter Municipal Consortia for Food Security and Local Development (Consads) and Citizenship Territories. Each of these has been elaborated within existing Governmental Programs. The objective has been to initiate the development process on a territorial basis, a challenge that is the foundation of the vast majority of the development policies in process. These policies have been targeted primarily to economically depressed rural areas where, after attempting a strategy that strengthened the endogenous capacity for development, the government by means of the citizen territories combines bottom-up with top-down actions, recognizing thus the importance of the role of the State, particularly in the conditions of those territories.
\end{abstract}

Keywords: public policies, rural development, territorial development, depressed rural territories.

\section{Resumen}

En los últimos años, en Brasil se implementaron políticas de desarrollo rural que han promovido la constitución de arreglos socioproductivos territoriales como estrategia de desarrollo rural. Ejemplos de eso son los Consejos de Seguridad Alimentaria y Desarrollo Local (Consads) y los Territorios de la Ciudadanía. Esas experiencias buscan generar la chispa que detone el proceso de desarrollo, desafío que está en la base de la gran mayoría de las políticas de desarrollo que utilizan el enfoque territorial como estrategia de implementación. Esas políticas se han orientado, prioritariamente, a los territorios rurales económicamente deprimidos, donde después de intentar con una estrategia que apostaba a la capacidad endógena de promover el desarrollo, el gobierno, mediante los territorios de ciudadanía, combina acciones buttom-up con acciones top-down, reconociendo así la importancia del papel del Estado, particularmente en las condiciones en que se encuentran aquellos territorios.

Palabras-clave: políticas públicas, desarrollo rural, desarrollo territorial, territorios rurales deprimidos

\footnotetext{
*Universidad Federal de Uberlandia, Brasil. Correo-e: acortega@ufu.br.
} 


\section{Introducción}

La última década del siglo xx estuvo marcada por el entusiasmo con el que los defensores del mainstream económico anunciaban el fin de la historia y de las fronteras. Sin embargo, en el inicio de milenio, lo que se observa en realidad, contrariando aquellos pronósticos, es el surgimiento de nuevos espacios de construcción de proyectos para desarrollar la base territorial.

De esa manera, no sólo vimos constituir, durante los últimos años en Brasil, arreglos socioproductivos territoriales inducidos por políticas públicas, sino también la consolidación de estructuras de gobernanza privadas, también de base territorial, y que vienen coordinando cadenas productivas para la ampliación de la escala, con miras a ampliar su capacidad competitiva en los más dinámicos mercados nacionales e internacionales.

En este trabajo nuestra preocupación son los arreglos territoriales constituidos por inducción del gobierno central, dirigidos particularmente al espacio rural, y que se han constituido a partir de la implementación de un modelo de desarrollo que considera proyectos reivindicados desde la base para superar una situación de subdesarrollo. Esos son los casos de los Consorcios Intermunicipales de Seguridad Alimentaria y Desarrollo Local (Consads), creados en el ámbito del Programa Hambre Cero, y los Territorios Rurales de la Secretaría de Desarrollo Territorial del Ministerio de Desarrollo Agrario, que en los últimos meses transformó 60 de ellos, en Territorios de la Ciudadanía.

Esas experiencias, en última instancia, buscan generar la chispa que detone el proceso de desarrollo, desafío que está en la base de la gran mayoría de las políticas que utilizan el enfoque territorial.

Por consiguiente, podríamos preguntar: ¿por qué las políticas de fortalecimiento de lo local ganan tanta expresión en un mundo globalizado que, de acuerdo con los anuncios del mainstream, representarían el fin de las fronteras? Porque, de acuerdo con Haesbaert (2006), el fenómeno de la desterritorialización como consecuencia del proceso de globalización es un mito, y a lo que asistimos es una des(re)territorialización del mundo. En este sentido, el autor afirma:

El mito de la desterritorialización es el mito de los que imaginan que el hombre puede vivir sin territorio, que la sociedad puede existir sin territorialidad, como si el movimiento de destrucción de territorios no fuese siempre, de algún modo, su reconstrucción en nuevas bases. [De ese modo] el grande dilema de ese inicio de milenio [...] no es el fenómeno de la desterritorialización [...] sino el de la multiterritorialización [...] de experimentar diferentes territorios al mismo tiempo, reconstruyendo constantemente el nuestro (Haesbaert, 2006: 16). 
Así, podemos preguntar cuáles son las condiciones y perspectivas concretas para el desarrollo territorial en el proceso de transformación económica de la globalización. En ese sentido, la pregunta a responder es: ¿ cómo cada territorio puede y debe moverse en un abrumador proceso de cambios globales, que penetra e influye en todos los espacios, y cómo las políticas de desarrollo territorial pueden contribuir con ese desafío?

En el primer apartado de este artículo presentamos el contexto histórico en que las experiencias de desarrollo territorial se consolidaron a partir de la década de los años setenta para servir de referencia a agencias multilaterales, como el Banco Mundial, que recomendaron la descentralización de la gestión pública, fundamentada en la organización de arreglos territoriales socioproductivos para superar las situaciones de subdesarrollo. A pesar de esa recomendación desde las altas esferas, acatada por los gobiernos centrales de los países en desarrollo, no se puede ignorar que en la base también se debe registrar una reivindicación para implementar políticas descentralizadas. Para eso es preciso observar que el proceso de redemocratización en América Latina en general, y en el Brasil en particular, fortaleció ese movimiento. En el caso de Brasil, basta revisar la Constituyente de 1988, promulgada con una orientación descentralizadora, tanto político-administrativa como de recursos presupuestales.

En un segundo apartado presentamos, si bien sucintamente, las políticas públicas más importantes que se han implementado en el país y que utilizan el enfoque territorial para promover el desarrollo rural. Esas políticas se orientaron sobre todo a los territorios económicamente deprimidos,${ }^{1}$ donde después de probar una estrategia que apostaba a la capacidad endógena de promoción del desarrollo, el gobierno implementó los Territorios de la Ciudadanía para combinar acciones buttom-up con las top-down, reconociendo así la importancia del papel del Estado, particularmente en las condiciones en que se encuentran tales territorios.

En ese sentido, estimamos que el gobierno brasileño tuvo que reconocer que, como país en desarrollo, y en especial en sus territorios deprimidos, encontramos enormes y particulares dificultades para promover el desarrollo, ya que

el grande dilema [es] el de la desigualdad entre las múltiples velocidades, ritmos y niveles de desreterritorialización, especialmente aquella entre la minoría que tiene pleno acceso y usufructa los territorios-red globales que aseguran su multiterritorialidad, y la masa o los "aglomerados" crecientes de personas que viven

\footnotetext{
${ }^{1}$ Estos territorios los constituyen municipios con bajos niveles de desarrollo, ritmo de crecimiento y potencial de desarrollo. Sus indicadores sociales (educación, salud y mortalidad) se ubican por debajo de la media nacional, al igual que su capacidad institucional (estimada por el grado de participación local en su gestión, así como su capacidad financiera y gerencial).
} 
en la más precaria territorialización o, en otras palabras, más incisivas, en la más violenta exclusión y/o reclusión socioespacial (Haesbaert, 2006: 372).

Éste, por tanto, es el gran desafío de la política de desarrollo territorial rural brasileña y latinoamericana: promover la inclusión socioespacial de amplias capas de nuestra población.

Por ello en nuestras investigaciones priorizamos identificar las potencialidades y los límites de la adopción de políticas de enfoque territorial, que no se pueden tomar como panacea para el rescate del proceso histórico de exclusión social y de inserción de aquellos territorios en los circuitos comerciales de bienes y servicios más competitivos. Además de las dificultades intrínsecas al proceso de desarrollo territorial, no podemos ignorar las asimetrías de poder en los territorios, tanto inter como intraclases, que puedan ser preservadas, o inclusive ampliadas, en función de los modelos de gobernanza inducidos por las políticas públicas.

Finalmente, a manera de conclusión, proponemos algunas ideas para llamar la atención en que, para que las estrategias de desarrollo que utilizan el enfoque territorial sean exitosas, particularmente en los territorios deprimidos, no se puede abandonar el papel intervencionista del Estado. Así, se ponen en jaque verdades relativas que circularon en todo el mundo en la última década.

\section{El contexto histórico-teórico del uso reciente del aporte territorial}

\subsection{El enfoque en el territorio: contextualización histórico-teórica}

En tiempos de globalización, el uso del enfoque territorial lo han recomendado científicos, gobiernos y agencias multilaterales. El concepto de territorio, ${ }^{2}$ sin embargo, adquirió un carácter polisémico. Por ello en este apartado presentamos algunas visiones destacadas sobre el tema, las cuales han estado presentes en importantes debates. Con esto esperamos dar mayor claridad en el análisis de las siguientes secciones, cuando se analizan algunas políticas gubernamentales brasileñas en que se utiliza el enfoque territorial en su sentido instrumental y práctico.

${ }^{2}$ Las políticas públicas de desarrollo rural recientes utilizan el criterio territorial en su implementación, y lo hacen a partir del incentivo de la constitución de territorios zonas, es decir, en espacios continuos. Entendemos, por tanto, los territorios como espacios delimitados donde en su interior se practican diferentes tipos de intercambio (inclusive poder), y con el exterior (otros territorios, localidades, espacios regionales o nacionales y la economía internacional) con una perspectiva de competitividad territorial que combina las dimensiones económica, social, ambiental y política (Sepúlveda et al., 2003). En consecuencia, se utiliza la noción de territorio como una "construcción territorial, y presupone un proyecto (de escala regional/territorial) concertado socialmente y detonador del desarrollo” (Mohar, 2008: 25). 
A pesar del modismo, que acaba por banalizar el concepto, nuestra intensión es verificar la pertinencia del uso del enfoque territorial en el proceso de des(re)territorialización en virtud del avance de la globalización. La desterritorialización es una de las características señaladas como consecuencia del proceso de globalización, en la medida en que se alcanzaría una ciudadanía universal y las fronteras perderían sentido. En esa perspectiva, se toma como supuesto la deslocalización económica, la fragilidad de las fronteras políticas (inclusive nacionales) y la hibridez cultural para caracterizarlo. Sería en este caso, el propio fin de los territorios. ${ }^{3}$

Por el contrario, y coincidiendo con Haesbaert,

defendemos la idea de que mucho de lo que los autores denominan desterritorialización es, en verdad, la intensificación de la territorialización en el sentido de una "multiterritorialidad", ${ }^{4}$ un proceso concomitante de destrucción y construcción de territorios mezclando diferentes modalidades territoriales (como los "territorios-zona" y los "territorios-red"), en múltiples escaladas y nuevas formas de articulación territorial (2006:32). ${ }^{5}$

En esa perspectiva, cuestionamos la homogenización esperada por muchos en función del proceso de globalización, y resaltamos, por tanto, su no linealidad y no monolitismo. Pues como enfatiza Reis (2002), aunque aceptemos la tesis de la convergencia provocada por la globalización, necesitamos reconocer la capacidad de iniciativas territoriales para tornarse globales. Es decir, para este investigador portugués, "la noción de globalización sólo puede ser útil si estuviese dotada de cualidades que le permitan comprender las dinámicas del mundo" (2002: 107), y que no es única. Por

\footnotetext{
${ }^{3}$ Sobre este tema se puede consultar Haesbaert (2006), en particular los capítulos 2 y 3.

${ }^{4}$ Cassiolato y Szapiro, apud Storper (2007), consideran que "la territorialidad está ligada a interdependencias específicas de la vida económica y no puede ser definida meramente como la localización de la actividad económica. Es mucho más, en el sentido de que está ligada a la dependencia de la actividad económica en relación con recursos territorialmente específicos. Las relaciones de proximidad geográfica se constituyen así, en activos específicos valiosos en la medida en que son necesarias para la generación de spillovers y externalidades positivas en un sistema económico. Una actividad es totalmente territorializada cuando su viabilidad económica está enraizada en activos (incluyendo prácticas y relaciones) que no están disponibles en otros lugares y que no pueden ser fácilmente o rápidamente creados o imitados en lugares que no las tienen" (2003: 40).

${ }^{5}$ De acuerdo con Schneider y Tartaruga (2006), por territorios-zona se entiende los espacios continuos de dimensión escalar que lo constituyen, mientras que los territorios-red son articulaciones entre espacios discontinuos de diferentes escalas. Es decir, los territorios-zona se podrían caracterizar por superficies, mientras que los territorios-red por puntos. Cassiolato y Szapiro (2003), a su vez, utilizan el concepto de red de manera distinta. Para esos autores, una red se caracteriza por la aglomeración de micro y pequeńas empresas en un determinado territorio y sin la presencia de una gran empresa coordinadora. En esta obra, en la que nos dedicamos fundamentalmente a las políticas públicas que inducen la constitución de consejos locales (municipales e intermunicipales) de desarrollo, la continuidad espacial es uno de los requisitos adoptados para su implementación, aunque reconocemos la posibilidad de que aparezcan redes en el interior de los territorioszona, o inclusive interzona.
} 
tanto, es preciso reconocer que el proceso de globalización tiene efectos en los diferentes territorios, que reaccionan de distintas maneras.

Evidentemente, y de acuerdo con los autores citados, no negamos la amplitud de las relaciones jerárquicas que estructuran la economía mundial, sino cuestionamos las potencialidades de los territorios, que por medio de acciones colectivas han promovido el desarrollo local y territorial. En otras palabras, estamos tratando de comprender las posibilidades para el desarrollo endógeno de economías con dinámicas territorializadas, basadas en la cooperación, aprendizaje, conocimientos tácitos y culturas técnicas específicas y en interrelaciones sinérgicas (Reis, 2002: 116).

Nuestro objetivo, por tanto, es analizar cómo por medio del enfoque territorial, acciones recomendadas desde arriba por agencias multilaterales y gobiernos nacionales, y reivindicadas desde la base por los movimientos sociales localistas, podemos vislumbrar potencialidades y limites para detonar un proceso de desarrollo, sobre todo en territorios rurales deprimidos en realidades de subdesarrollo.

En las últimas décadas, en el ámbito académico y en las agencias multilaterales se construyó un aparente consenso en torno a la descentralización de la acción pública viabilizada por la adopción de políticas que fuesen capaces de representar la chispa detonadora del desarrollo. En ese sentido, el enfoque territorial gana fuerza en todo el mundo, y particularmente en los países latinoamericanos. De acuerdo con Fiori,

el tiempo político-económico inaugurado por la revolución soviética y por la crisis de los ańos treinta, reforzado por la reconstrucción económica y por la guerra fría después de la segunda Guerra Mundial, fue un tiempo de centralización del poder; fuese en la forma de los welfare states, de los Estados socialistas o de los Estados desarrollistas, independientemente de la naturaleza democrática o autoritaria de sus gobiernos (1995: 20).

No obstante, Fiori reconoce que "hoy ya hay un total consenso" en torno a las políticas descentralizadoras, y que "Esa propuesta de descentralización adquirió extensión universal ocupando un espacio cada vez mayor en el discurso programático de todos los partidos políticos, independientemente de su posición en el espectro político-ideológico clásico" (1995: 20).

Para la derecha política, a partir de su diagnóstico sobre la crisis de gobernabilidad de las democracias, es necesario reducir la participación pública del Estado. De esta manera, la descentralización de las instancias administrativas, así como las que toman las decisiones, surge como alternativa necesaria para superar la crisis, pues permitiría mayor autonomía local de los proyectos de desarrollo endógeno, sin que el Estado central tuviera que aportar grandes montos de recursos. 
Para fortalecer esa posición, agencias multilaterales -Banco Mundial (вм), Banco Interamericano de Desarrollo (BID), Fondo Internacional para el Desarrollo Agrícola (FIDA), Instituto Interamericano de Cooperación para la Agricultura (IICA), Organización de las Naciones Unidas para la Alimentación y la Agricultura (FAO) y Comisión Económica para América Latina y el Caribe (CEPAL), entre otras- en los últimos años aprobaron estrategias de desarrollo que adoptaron el enfoque territorial. Un documento del Banco Mundial, por ejemplo, dirigido particularmente a América Latina, recomienda la creación de nuevas institucionalidades (arreglos socioproductivos locales) para el medio rural como forma de alcanzar una buena gobernanza. De esa manera: "The combination of increased decentralization and the development of local democracy are key elements to progressively create the conditions for greater participation and accountability at the local level" (вм, 2001).

Desde otra perspectiva, fuerzas de una nueva izquierda, como la define Fiori, también reivindican la descentralización del poder. Para esa izquierda, ése es el "camino para desactivar la burocratización del welfare state y profundizar la participación ciudadana en las estructuras y procesos democráticos, aumentando la visibilidad y el control de los sistemas decisorios" (Fiori, 1995: 20).

En el caso de los países latinoamericanos, Fiori (1995) concluye que el proceso de descentralización del poder y la reorganización democrática de los Estados se ha dado por medio de un federalismo que se puede denominar pragmático o reactivo, transfiriendo poder a las instancias subnacionales. A partir de los años ochenta ése ha sido el discurso antiautoritario inscrito en los proyectos de gobierno o en las reformas constitucionales de prácticamente todas las fuerzas democráticas del continente. De esa manera, el federalismo emergente se pude entender como sinónimo de descentralización.

En constituciones nuevas o reformadas del continente centro-sudamericano, se aprobaron proyectos de descentralización fiscal y autonomía político-administrativa. Sin embargo, las legislaciones rápidamente fueron cuestionadas en la medida en que la crisis económica latinoamericana se profundizaba, evidenciada por la crisis de la deuda externa a principios de los años ochenta, que excluyó esta fracción continental del sistema financiero internacional. En nombre de la estabilización y del ajuste estructural, la descentralización fiscal, todavía como una propuesta vaga, se revisó. Como consecuencia, cuando analizamos más detenidamente tal proceso, constatamos que las transferencias de responsabilidades no se acompañan de transferencias de recursos financieros adecuados para ejecutar las responsabilidades asumidas. Esa constatación es evidente cuando verificamos las participaciones de los recursos presupuestales de 
las localidades en comparación con las disponibilidades de las instancias superiores (Finot, 2005). ${ }^{6}$

De esta manera, "las estrategias de ajustes a las nuevas condiciones económicas internacionales, sobre todo aquellas impuestas por el peso de la deuda, acabaron convergiendo en dirección al llamado programa neoliberal de estabilización y reformas estructurales destinadas a disminuir la presencia económica de los Estados, desregular el mercado y 'abrir las economías nacionales”" (Fiori, 1995: 31).

Como consecuencia, se puede decir que todavía existe una distribución asimétrica de los recursos, y los beneficios que podría tener la descentralización los terminan captando principalmente las regiones y localidades más desarrolladas, que disponen de medios y capacitación para desempeñar las funciones que les fueron atribuidas. De esa forma, se mantienen, o incluso se agravan, las disparidades interregionales.

Más recientemente, por consiguiente, la propuesta de descentralización se puede ver como estrategia de desarrollo autónomo y endógeno ${ }^{7}$ de los territorios/regiones/localidades/instancias subnacionales, buscando aquello que el Banco Mundial denomina enabling economic environment (ambiente económicamente viable y sustentable), que fue señalado como condición esencial de la gobernabilidad.

Por otro lado, no podemos ignorar que, desde la base, también tenemos una reivindicación para la implementación de políticas descentralizadas. Para eso, es necesario observar que el proceso de redemocratización en América Latina fortaleció ese movimiento. En el caso de Brasil con la Constitución de 1988, denominada por el ex diputado Ulises Guimarães, Constitución Ciudadana, tenemos una fuerte orientación descentralizadora tanto político-administrativa como de recursos.

Así, el tema del desarrollo local ganó presencia en América Latina en general, y en Brasil en particular, como consecuencia de diversos factores, entre los cuales destacamos los siguientes:

1. Fortalecimiento de fuerzas locales en la lucha por la redemocratización en varios países. La victoria de la sociedad civil, más organizada en la formulación y gestión de políticas públicas (participación

\footnotetext{
${ }^{6}$ En el caso latinoamericano, Brasil es uno de los países que promovió una mayor descentralización del presupuesto en las últimas décadas. Aun así, concentra más de $60 \%$ de los recursos. México, un caso intermedio, concentra aproximadamente $70 \%$, mientras que el caso más extremo, Chile, concentra en el gobierno central casi 90\% de los recursos presupuestales (Finot, 2005).

7 Esa estrategia de desarrollo se puede considerar autónoma, "porque es gobernada por reglas específicas que gobiernan su estructura y dinámica" (Favareto, 2007: 188), y endógena porque es "un proceso de crecimiento económico que implica una continua ampliación de la capacidad de agregar valor sobre la producción, así como de la capacidad de absorción de la región, cuya expansión es la retención del excedente económico generado en la economía local y/o la atracción de excedentes provenientes de otras regiones" (Amaral, 2001).
} 
en consejos locales, difusión de la propuesta de presupuestos participativos, etc.), generó un proceso de lucha por la democracia mediante los espacios locales. Así, en oposición a los regímenes autoritarios y/o centralizados, surgen nuevos actores sociales, militantes localistas que divisaron, en las visiones apologéticas de desarrollo local, la posibilidad de tomar el futuro en sus manos. De esa forma buscaron espacios para la construcción de un modelo de desarrollo que negaba las políticas de desarrollo centradas en la planeación top-down (Moyano, 1999), que desestimaban las opiniones de la sociedad local con respecto a los proyectos formulados por el gobierno central a favor de un modelo bottom-up, en el que la sociedad local, de manera participativa, elige y construye los proyectos prioritarios para su desarrollo. ${ }^{8}$

2. Motivación institucional. Como resultado de las demandas desde la base y del estímulo de las agencias multilaterales, las políticas gubernamentales han incentivado, en mayor o menor intensidad en los países latinoamericanos, el avance del proceso de descentralización, ampliando las responsabilidades de instancias subnacionales para formular y gestionar políticas públicas. Para apoyar la gestión de esas políticas se han hecho arreglos sociales locales (consejos), algunos de carácter sólo consultivo pero también otros deliberativos. Esa nueva cultura de formulación y gestión de políticas públicas valora los espacios de concertación social en la búsqueda de alternativas al desarrollo (Dagnino, 1994, 2002).

Así, es interesante observar que la recomendación de las agencias multilaterales fue al encuentro de las aspiraciones de los militantes del localismo, que anhelaban apartar al gobierno central de los procesos de desarrollo local. Actualmente, esas posiciones contribuyen a confundir las discusiones en torno al papel del Estado, pues crean un aparente consenso alrededor del tema del desarrollo local, una vez que ambos (agencias multilaterales y localistas) reivindican las posibilidades para construir un modelo de desarrollo local autónomo y endógeno. ${ }^{?}$

3. Desregulación de la economía. En la línea del llamado Consenso de Washington, la década de los noventa estuvo marcada por un intenso proceso de desregulación de la economía. Así se siguió la onda neoliberalizante que se hizo hegemónica mundialmente, y se

\footnotetext{
${ }^{8}$ Acerca de la planeación de abajo para arriba y de arriba para abajo, véase Moyano (1999).

${ }^{9}$ Recientemente, el propio Banco Mundial reconoció en sus informes la incapacidad de las políticas liberales para alejar a los países de su situación de subdesarrollo. Al contrario, concluye que fueron los países que en la segunda mitad del siglo xx acentuaron sus estrategias de crecimiento con base en una mejoría en la distribución de la renta y activos, los que se encuentran en mejor situación.
} 
redujo la participación del Estado en la economía. De esta manera la hegemonía neoliberal apunta a la descentralización para el desarrollo autónomo y endógeno, para la autogestión. Pero podemos cuestionar: ¿con qué recursos?

Como alternativa al espacio dejado por el Estado, se observa el surgimiento de importantes experiencias autónomas de concertación social orientadas a ocupar nuevamente espacios de intervención que antes estaban a cargo del Estado. Surgen así tanto espacios de concertación social-local, con miras a la construcción de proyectos de desarrollo más amplios, como arreglos productivos locales que prevean la regulación de cadenas productivas para concesión de certificados de origen.

Por tanto, en una etapa en que se amplía la participación de la sociedad civil organizada en los procesos de toma de decisión, es preciso comprender que las transformaciones económicas, políticas y sociales latinoamericanas acabaron fortaleciendo experiencias locales de organización en torno a la búsqueda de objetivos comunes. De esa forma, en esos espacios locales, la mayoría de las veces de carácter rural, ${ }^{10}$ es donde se debe reconocer la participación de los actores sociales colectivos (organizaciones de carácter económico o político).

De esta manera, si la preocupación de reducir las disparidades continúa en el orden del día, al intentar entender la capacidad de las políticas de descentralización para promover el desarrollo en los llamados territorios deprimidos, el enfoque territorial puede contribuir al agravamiento de aquella situación. Por ello, en nuestro concepto es preciso tener claridad en las potencialidades y los límites del enfoque localista, que no puede, por tanto, tomarse como panacea para insertar aquellos territorios en los circuitos comerciales de bienes y servicios.

En ese sentido, no es posible ignorar las asimetrías de poder en los territorios inter e intraclases. Así, para que se promueva un proceso de desarrollo menos desigual, es necesario reducir esas asimetrías de poder económico, político y social. Sin duda alguna, un gran desafío.

\subsection{Algunos principios innovadores}

Primero es necesario reconocer que las actuales políticas que utilizan el enfoque territorial rural se han elaborado tomando como referencia algunos principios que, a nuestro entender, son innovadores. Así, lo rural no

\footnotetext{
${ }^{10}$ Por rural consideramos no sólo las actividades en ese espacio estricto (agropecuarias y no agropecuarias), sino también los centros urbanos de municipios con baja densidad demográfica, población pequeña y donde predominan aquellas actividades en la economía local (Veiga, 2002).
} 
se toma como sector económico, es decir, lo rural no es sólo lo agropecuario; se procura superar la vieja dicotomía rural-urbana en la orientación de las políticas públicas, e incluso se supera la orientación de políticas anteriores en las que la localidad significaba el municipio, para dirigirlas hacia arreglos territoriales intermunicipales.

\subsubsection{Rural es espacio y no sector}

Más allá que en un aspecto cuantitativo, investigaciones han contribuido a cuestionar algunos conceptos y visiones tradicionales sobre el medio rural brasileño. Algunas de ellas señalan que el concepto de lo rural no se puede identificar exclusivamente con las actividades agropecuarias.

Esa identificación exclusiva ya no era verdadera en otras épocas. Actualmente la interrelación agricultura-industria y campo-ciudad se torno aún mayor, aumentando la heterogeneidad y la complejidad del medio rural. En estos términos, lo rural no se puede tomar sectorialmente como sinónimo de actividades agropecuarias.

Para Veiga (2002) lo rural se caracteriza como un espacio de menor grado de artificialidad del ambiente en comparación con áreas urbanas, menos densidad poblacional y mayor peso de los factores naturales, manteniendo así sus especificidades. Para este autor, sin embargo, en Brasil es necesario adoptar una perspectiva más amplia de lo que es rural, atada todavía a la definición legal de que toda sede de municipio es ciudad y, por exclusión, todo lo que está fuera del perímetro urbano es rural, y a éste se asocia lo agropecuario. Por consiguiente, se tienen dos problemas: identificar lo rural exclusivamente con lo agropecuario y considerar toda sede de municipio como ciudad. ${ }^{11}$

Para Graziano da Silva, lo rural "sólo puede ser entendido como un continuo de lo urbano desde el punto de vista espacial; y desde el punto de vista de la organización de la actividad económica, las ciudades no pueden más ser identificadas apenas con la actividad industrial, ni los campos con la agricultura y la ganadería" (1999: 1).

En estos términos, se corrobora un proceso de urbanización del campo que está diluyendo la tradicional dicotomía urbano-rural. Lo tradicional cede lugar ante el nuevo rural. Una novedad que no representa un carácter inédito de las actividades no agrícolas, pero sí su mayor importancia en la dinámica de esos espacios, sin despojar a las actividades agropecuarias de su relevancia. ${ }^{12}$

\footnotetext{
${ }^{11}$ Para un mayor conocimiento de la obra de José Eli da Veiga, véase su sitio personal: www. econ.fea.usp.br/zeeli.

${ }_{12}$ Para profundizar en el tema véase la página del Proyecto Rurbano: www.eco.unicamp.br/ pesquisa/NEA/pesquisas/rurbano.
} 
Independientemente de una u otra visión, es cierto que, como sustenta Abramovay (2003), la ruralidad se está transformando cada vez más en un valor para las sociedades actuales. Y más allá de un espacio dominado por las actividades productivas sectoriales (agropecuarias), el medio rural se transforma cada vez más en un espacio de variadas actividades basadas en relaciones sociales que combina una multiplicidad de actores diferentes. En suma, un nuevo contexto abre nuevos desafíos y posibilidades para el desarrollo del medio rural, incluso de aquellos territorios deprimidos.

Es sobre esa nueva realidad en transformación que el estudio territorial ganó importancia en la formulación de las políticas públicas brasileñas dirigidas a los territorios rurales a partir de la década de 1990. Y en la base de esas propuestas está el reconocimiento de las diversidades territoriales para formular políticas de desarrollo.

A pesar de que están vinculadas a un contexto histórico específico, se reconoce que esas diversidades se pueden potencializar mediante políticas que valoricen la organización de esos territorios alrededor de objetivos comunmente pactados, contribuyendo así con un proceso de desarrollo sustentado.

De acuerdo con Campanhola y Graziano, "el proceso de desarrollo local trae consigo nuevas perspectivas de adecuación de las políticas públicas nacionales a las peculiaridades regionales, y de los espacios urbanos y rurales en su dimensión física, económica, social y cultural respetando, por consiguiente, todos los preceptos del desarrollo sustentable" (2000: 31).

Graziano da Silva (2001) enfatiza, inclusive, la importancia de traer la discusión de las políticas públicas federales a la esfera municipal. Para este autor, además de acercarla a la población más directamente involucrada, el enfoque en el desarrollo local permite que ese ámbito se democratice cada vez más, ampliando la participación de otros actores y no sólo la de aquellos representantes de la élite local, urbana o rural.

Ese proceso, no obstante, en el caso brasileño, debe tomar en consideración sus especificidades. Entre ellas, se destacan las desigualdades sociales y regionales, resultado de problemas histórico-estructurales de la sociedad brasileña.

\subsubsection{Superar la dicotomía rural-urbana}

El conjunto de transformaciones que está ocurriendo en el ámbito mundial, sobre todo a partir de la década de 1980, ha influido fuertemente esa relación rural-urbana. Un contexto caracterizado por un proceso ampliado de interdependencia de las relaciones económicas, sociales, culturales y políticas, entre otras. 
Según Graziano (1999), la utilización que los autores clásicos (como Marx y Weber) daban al corte urbano-rural se relacionaba con el conflicto entre dos realidades sociales diferentes (una en declive, otra en ascenso) en función del progreso de las fuerzas capitalistas que minaban el viejo orden feudal. La dicotomía urbano-rural buscaba representar, por tanto, las clases sociales que contribuyeron al surgimiento del capitalismo o que se oponían a él en la Europa del siglo XviI y no propiamente un corte geográfico. A partir de ahí lo urbano se identificó con lo nuevo, con el progreso capitalista de las fábricas; y lo rural, o la clase de los propietarios rurales, con lo viejo (es decir, el viejo orden social vigente) y con el atraso en el sentido de que procuraban impedir el progreso de las fuerzas sociales, por ejemplo, en la famosa disputa por la revocatoria de las leyes que limitaban la importación de cereales por la Inglaterra en la época de Ricardo.

Por tanto, en la actualidad, en que esa separación pierde sentido, no solamente por la intensa integración de actividades agropecuarias, industriales y de servicios, sino también porque el lugar de asentamiento no identifica una u otra actividad, las políticas públicas no pueden continuar orientadas estrictamente a lo rural, y menos aún exclusivamente a lo agropecuario. En nuestro caso, inclusive, cuando tomamos como referencia lo rural, aceptamos la propuesta de Veiga (2002), que al cuestionar el criterio con que el Instituto Brasileiro de Geografía e Estadística (IBGE) define campo y ciudad, y dado por ley desde 1934, transforma toda sede de municipio en ciudad. Se ignoran así criterios internacionales más aceptados para caracterizar lo que es una ciudad, que requiere equipamientos y vida urbana distinta de la gran mayoría de nuestras ciudades. De acuerdo con Veiga (2002), si adoptamos esos criterios internacionales, de los más de 5,500 municipios que existen actualmente en Brasil, más de 4,500 serían rurales, por lo que las políticas públicas dirigidas a lo rural deberían incluirlos.

\subsubsection{Carácter intermunicipal de los arreglos socioproductivos}

La búsqueda de sinergias locales con miras a elaborar un proyecto intermunicipal de desarrollo permite explorar las ventajas comparativas y competitivas de cada municipio. Esos arreglos socioproductivos requieren realizar el diagnóstico de los principales problemas del territorio y elaborar planes de desarrollo. Para ello se busca articular políticamente los municipios con el objetivo de crear condiciones para que se firme un pacto intermunicipal de desarrollo con miras al desarrollo territorial. De esa manera, es necesario reunir líderes locales -como alcaldes y sus delegados-, representantes de entidades empresariales, de los trabajadores, de los agricultores y de organizaciones de la sociedad civil. 
Las estrategias de desarrollo local, como otras políticas recientes, oficiales o propuestas, que buscan la institucionalización del desarrollo sustentable del país, convergen en cuanto al papel destinado a la articulación microrregional de municipios como instrumento que posibilita la gestión integrada y compartida, la racionalización del empleo de los recursos endógenos y exógenos, la participación de la sociedad organizada y el control social (IвAм, 2003: 16).

Sin embargo, ese recorte intermunicipal no necesariamente mantiene una correlación con las microrregiones geopolíticas establecidas por el IBGE. La idea, tanto en el caso de los Consads como en el de los Territorios Rurales de MDA, es incentivar la constitución de consorcios a partir de experiencias de articulación intermunicipales ya en marcha, o identificar municipios cuyas especificidades comunes vislumbren potenciales pactos por el desarrollo. Así, se propone constituir consejos intermunicipales como instancia máxima propositiva y deliberativa del sistema de desarrollo local microrregional, y que deberá reflejar la pluralidad de representación de los consejos municipales. Los consorcios son, por tanto, una forma de asociación entre municipios, con participación de la sociedad civil y del poder público, para acciones que en conjunto generen empleos e ingresos.

La acción de los consorcios parte de la propuesta de que la integración territorial es fundamental para mejorar las condiciones de inserción de los municipios empobrecidos y pequeños en la dinámica del territorio nacional, para proveer a esas localidades de mejores condiciones de competitividad, solidaridad sistémica y de mayores posibilidades para asegurar la atención de las necesidades básicas de sus municipios. A través de los consorcios se pretende hacer permanente la articulación entre el poder público y la sociedad civil para promover acciones de desarrollo de forma institucionalizada.

\section{Los Territorios Rurales inducidos por políticas públicas}

Políticas de desarrollo rural. Como destacamos antes, las recientes políticas de desarrollo rural han utilizado el enfoque territorial en su implementación a partir de la constitución de zonas territoriales.

En la implementación de esas políticas de desarrollo territorial algunos de los supuestos que se consideran son: 1) nivel alto de pobreza en ambientes rurales (campo y municipios de perfil rural); 2) lo rural se toma como un espacio y se diferencia del enfoque que lo considera como sector agropecuario; 3) el proceso de desarrollo se debe dar mediante la inclusión de las actividades realizadas en lo rural en mercados dinámicos (regionales, nacionales e internacionales); 4) con la introducción de innovaciones tecnológicas productivas y organizacionales, reformas institucionales y la 
creación de nuevos modelos de gobernanza local se debe llevar a cabo la descentralización administrativa y/o política, y 5) esa nueva gobernanza se sustentaría en función de una concertación social, cuyo resultado es un pacto territorial (inter e intraclases y público-privado) con miras al desarrollo endógeno.

Así, el enfoque territorial ha sido exaltado como alternativa para el desarrollo de municipios de perfil agrario y, particularmente, con predominancia de la agricultura familiar. En el caso de Brasil, es importante destacar dos experiencias: los Consorcios Intermunicipales de Seguridad Alimentaria y Desarrollo Local (Consads) y los territorios rurales del MDA.

Los Consads. De acuerdo con documentos oficiales, el objetivo básico del Programa Hambre Cero (pFz) era la "erradicación del hambre a través de acciones integradas y estructuradas por una política nacional permanente de seguridad alimentaria y nutricional" (PFZ, 2003: 3). En el campo de las acciones territoriales, la instalación de los Consads constituyó una estrategia de cooperación entre el poder público y la sociedad civil, dirigidos al fomento, apoyo logístico y canalización de recursos para las iniciativas territoriales, proyectos y acciones estructurales, orientados a generar empleo e ingreso, con la garantía de seguridad alimentaria y desarrollo local.

En el año 2003 se constituyeron 40 Consads diseminados por el país, de los cuales 26 se crearon considerando la implementación de uno por estado de la federación, y 14 más en los que el criterio era su localización en las regiones Norte y Nordeste: Consads interestatales que reúnen un mayor número de municipios que participan del programa tarjeta alimentación y ubicados en mesorregiones diferenciadas de los ministerios de Integración Nacional y de Planeación, Presupuesto y Gestión. ${ }^{13}$

En última instancia, la selección de esos territorios se hizo con los siguientes criterios: "Municipios con bajos índices de desarrollo humano y pequeña población, territorialmente excluidos de los éxitos de acumulación de riquezas. Son municipios con perfil rural, con grandes carencias de infraestructura, cuya actividad económica y de subsistencia reside, en la mayor parte de los casos, en la agricultura familiar (Franca, 2003: 7).

La concepción de los Consads se basa en la noción de desarrollo local, cuya acción orientadora es buscar la seguridad alimentaria, que se alcanzaría no sólo mediante políticas y acciones compensatorias, sino también por medio de la búsqueda de una dinamización económica de los territorios atendidos. En ese sentido, conseguir la seguridad alimentaria en el

\footnotetext{
${ }_{13}$ Para conocer mejor los Consads, véase www.mds.gov.br/programas/seguranca-alimentar-enutricional-san/consad/encontros-regionais-consads.
} 
territorio se puede asimilar como una estrategia orientadora para el desarrollo de esos territorios deprimidos.

Para alcanzar ese objetivo se parte del principio de que los problemas locales y sus soluciones sobrepasan los límites municipales. En ese sentido, al enfrentar esos problemas, el apalancamiento ${ }^{14}$ (complementariedad) de las potencialidades, así como la construcción y fortalecimiento del capital social podrían tener mayor viabilidad si se llevan a cabo mediante una articulación entre grupos de municipios unidos por lazos de identidad social, cultural, ambiental, tecnológica o económica (IвAм, 2003)

De manera general, los Consads se encargan de: 1) la promoción de proyectos concebidos como resultado de pactos entre la sociedad civil y el poder público; y 2) el fortalecimiento del apoyo técnico y aval institucional para obtener recursos por medio de socios estatales, nacionales e internacionales.

Así, a partir de un diagnóstico de la realidad territorial y de la identificación de proyectos intermunicipales de desarrollo, se obtiene un planeamiento de tipo bottom-up. Para eso, los Consads deben constituir una organización centrada en una estructura decisoria que tenga un órgano máximo de deliberación con características de fórum y órganos de nivel decisorio gerencial y operacional. Las decisiones negociadas y pactadas en el fórum deben dar origen a un plan de acción, el cual se debe acompańar de un proceso de seguimiento y evaluación de procesos, resultados y efectos de las acciones implementadas. ${ }^{15}$

Hay dos modalidades de proyectos financiados por el gobierno federal para municipios incluidos en los Consads: 1) los que regularmente apoyan los MDs y que se ocupan de construcción de tanques, cocina comunitaria y popular y programa de adquisición de alimentos (compra directa local, agricultura urbana, y 2) los proyectos innovadores, que son los que surgen del Plan de Acción de los Consads y son aprobados por la asamblea del fórum.

Posteriormente, mediante políticas estructurales como contrapunto a las medidas de emergencia exigidas para la atención de poblaciones amenazadas por la inseguridad alimentaria, sus acciones se dirigen a construir bases sólidas que permitan a las poblaciones más pobres obtener empleo e ingreso. Se pretende, de esa manera, generar un ambiente socioeconó-

${ }^{14}$ A partir de la definición finaciera, como resultado de los recursos obtenidos de otras fuentes a partir del uso de recursos para llevar a cabo un proyecto.

${ }^{15}$ Además del fórum, los Consads cuentan con un consejo fiscal que revisa y aprueba sus cuentas; además de que también se encarga de implementar las acciones definidas por el fórum. El consejo lo constituye una representación que debe ser reflejo del fórum, que lo constituye en una instancia colegiada operacional. Esa operacionalización la realiza una secretaría ejecutiva por medio de sociedades con agentes gubernamentales en los tres niveles, con ONG, OsciP, entre otras. 
mico propicio para garantizar la seguridad alimentaria y la construcción de un proceso de desarrollo territorial.

En otras palabras, se reconoce que la cooperación entre municipios, a partir de una estrategia común de desarrollo que construya arreglos socioproductivos locales, hace viables acciones y proyectos fundamentales para la seguridad alimentaria que serían gravemente obstaculizados si fueran implementados por los municipios de forma aislada. Por tanto, con esa iniciativa se busca reconocer territorios constituidos por municipios cuya articulación alrededor de proyectos comunes puedan resolver mejor sus problemas de seguridad alimentaria y desarrollo local.

En un trabajo anterior (Ortega, 2008) indicamos algunas dificultades enfrentadas por los Consad para alcanzar los objetivos a ellos propuestos. Entre ellas destacamos la heterogeneidad entre los municipios seleccionados, que dificultan la concertación alrededor de un proyecto común; los problemas en función de la asimetría de poder, que no siempre permite la participación de todos los segmentos sociales; la dificultad para articular un acuerdo político vertical, desde el gobierno federal hasta los municipales; y una coordinación horizontal en las diferentes esferas del gobierno. Adicionalmente, se debe registrar el pequeño volumen de recursos para un proyecto tan ambicioso como es garantizar la seguridad alimentaria por medio de proyectos de desarrollo local. Para que se tenga una idea, en 2006, acciones orientadas a la seguridad alimentaria de los Consads recibieron del Ministerio de Desarrollo Social y Lucha contra el Hambre (MDs), por medio del Edital 01/2006, apenas cuatro millones de reales. Ese año se aprobaron 83 propuestas hechas por los 40 Consads de todas las regiones del país.

Los Territorios Rurales del MDA. Al principio del gobierno del presidente Lula, en el Ministerio de Desarrollo Agrario (MDA) se creó la Secretaría de Desarrollo Territorial (SDT) para reorientar la estrategia de las políticas de desarrollo rural de dicho Ministerio. Esa nueva estrategia, que tiene una perspectiva intermunicipal, acogió la propuesta que surgió en el $1^{\circ}$ Plan Nacional de Desarrollo Sustentable (1\% PNDRs), ideado en el año 2002 por el Consejo Nacional de Desarrollo Rural Sustentable. En este documento, el enfoque territorial es el eje central de sus propuestas, y terminó por constituirse en el centro de actuación de la SDT, creada en el año siguiente. ${ }^{16}$

\footnotetext{
${ }^{16}$ Puede causar extrañeza que una propuesta que surgió durante el gobierno de Fernando Henrique Cardoso se implementara en el gobierno de Lula. Sin embargo, es necesario recordar que el Consejo Nacional de Desarrollo Rural Sustentable lo componían representantes de la sociedad civil que comulgaban con la propuesta. Algunos de ellos, inclusive, pasaron a constituir el equipo del nuevo gobierno en el MDA.
} 
Así, los idealizadores de las propuestas gubernamentales del gobierno de entonces concordaban en que el enfoque territorial permitiría mayor capacidad de interlocución entre los poderes públicos y los actores sociales más organizados, comprometidos y sintonizados en torno a proyectos de desarrollo rural. Ese enfoque también promovería mayor articulación de los diferentes niveles del gobierno y de las organizaciones de la sociedad alrededor de un pacto territorial (Brasil, 2003). Es decir, permitiría consolidar un acuerdo político vertical desde los consejos intermunicipales, pasando por los consejos estatales para llegar al Consejo Nacional (Condraf).

El objetivo de la SDT sería, por consiguiente, encontrar una mejor integración y articulación de las políticas públicas de los gobiernos federal, estatal y municipal con la sociedad civil, en torno al desarrollo de territorios donde predominen agricultores familiares y beneficiarios de la reforma agraria (Brasil, 2003).

Con la creación de la SDT, la línea de financiamiento del Programa Nacional de Fortalecimiento de la Agricultura Familiar (Pronaf), dirigido a infraestructura y servicios, ${ }^{17}$ cambió su unidad de atención. Ésta pasó al desarrollo de territorios rurales de carácter intermunicipal y no municipal.

La estrategia de actuación principal de la SDT fue promover acciones descentralizadas que valoraran los potenciales endógenos locales en el proceso de desarrollo de esos territorios. Acciones con miras a "apoyar la organización y el fortalecimiento institucional de los actores sociales locales en la gestión participativa del desarrollo sustentable de los territorios rurales y promover la implementación e integración de las políticas públicas". ${ }^{18}$

La idea, por tanto, es unir los municipios en torno de un proyecto de desarrollo territorial por medio de la formación de nuevos arreglos intermunicipales que hagan viable un pacto territorial por el desarrollo. El desafío de la SDT era identificar y constituir los territorios a partir de la composición de identidades regionales como elemento aglutinador y promotor del desarrollo sustentable (Brasil, 2003).

Incluso se destaca que: "Son los territorios donde los criterios multidimensionales que los caracterizan, así como los elementos más sobresalientes que facilitan la cohesión social, cultural y territorial, presentan, explícita o implícitamente, el predominio de elementos 'rurales'. En estos

${ }^{17}$ El Pronaf tenía tres líneas principales de financiamiento a la agricultura familiar: costeo, inversión e infraestructura. Esta última se dirigía a los municipios con fuerte presencia de agricultura familiar, con la exigencia de constituir un consejo de desarrollo rural sustentable, donde participaran por lo menos $50 \%$ de representantes de los agricultores familiares. Sus recursos se dedicaban a la infraestructura municipal, y con la constitución de los Territorios Rurales, dichos recursos pasaron a la SDT para financiar esos territorios.

${ }^{18}$ Resolución núm. 37, del 16 de febrero de 2004 del Condraf. 
territorios se incluyen los espacios urbanizados que comprenden ciudades pequeñas y medias, villas y poblados (Brasil, 2003: 34; cursivas del autor).

De acuerdo con esta orientación, en 2003, con la creación de la Secretaría Nacional de Desarrollo Territorial del MDA, se empezaron a crear los Consorcios Intermunicipales de Desarrollo Rural Sustentable (los Territorios Rurales), de los que actualmente hay 160 en funcionamiento.

Esos territorios se crearon a partir de algunos supuestos innovadores: el enfoque territorial, la superación de los límites municipales, una visión de lo rural más allá del aspecto sectorial de la agricultura, una política de superación de la dicotomía rural-urbana, superar los conflictos intra e interclase por medio de un pacto territorial y promover el desarrollo endógeno. Un desafío nada fácil para territorios que, en su mayoría, se pueden calificar como deprimidos.

A pesar de esos esfuerzos de innovación, todavía está lejos alcanzar el objetivo de romper con cierto sesgo agrarista. De la misma forma, tampoco puede decirse que se ha superando con facilidad la rígida dicotomía rural-urbana, a pesar de las orientaciones que existen para que sea en sentido contrario. Analizando los proyectos financiados por la Secretaría de Desarrollo Territorial para atender las demandas de los Territorios Rurales, Ortega (2008) concluye que se mantiene el predominio de los proyectos de carácter agropecuario. Del total de proyectos aprobados durante los años 2003 a 2006, aproximadamente 45\% son agropecuarios, y los que no están ligados a las actividades agropecuarias o agroindustriales representaron, en el mismo periodo, sólo 1.36 por ciento.

\subsection{Territorios de la Ciudadanía}

Los Territorios de la Ciudadanía (TC) se difundieron con la perspectiva de que se constituyeran en uno de los ejes de acción del gobierno federal con miras a reducir las desigualdades. Así, por medio de esa política, se pretende superar la pobreza rural utilizando la estrategia del desarrollo territorial.

Para alcanzar este objetivo, el gobierno federal, en sus documentos oficiales de constitución de los TC, deja claro que la estrategia que utiliza es la inclusión productiva de las poblaciones pobres de los territorios, lo que requiere un gran conjunto de acciones gubernamentales coordinadas con la planeación e integración de políticas públicas, la búsqueda de la universalización de programas básicos de ciudadanía y la ampliación de la participación social. En el ańo 2008 se instalaron 60 TC y en 2009 otros 60 , con ello se alcanzó la meta prevista. ${ }^{19}$

${ }^{19}$ Véase http://www.territoriosdacidadania.gov.br/dotlrn/clubs/territriosrurais/one-community. 
Los TC se constituyeron a partir de los TR, donde se priorizaron los territorios que denominamos deprimidos. Por tanto, la elección e importancia del territorio a incluir en el Programa Territorios de la Ciudadanía requiere, como supuesto, su incorporación al Programa de Desarrollo Sustentable de Territorios Rurales, del Ministerio de Desarrollo Agrario. Los demás criterios de selección de los TR que se convirtieron en TC son los siguientes: tener los menores IDH (Índice de Desarrollo Humano), mayor concentración de agricultores familiares y asentados de la reforma agraria; más concentración de poblaciones quilombolas ${ }^{20}$ e indígenas; mayor número de beneficios del Programa de Bolsa Familia; más municipios con bajo dinamismo económico; mayor organización social; por lo menos un territorio por estado de la federación (Brasil, decreto del 22 de febrero de 2008).

En cuanto a las características económico-productivas de los TC, la SDT-MDA estima que 19 de los 60 instalados en el año 2008 están en regiones estancadas y 22 en áreas de bajos ingresos, mientras que 16 están en regiones dinámicas y tres en de altos ingresos. Por tanto, alrededor de $70 \%$ de los TC podemos caracterizarlos como territorios rurales deprimidos.

En el Programa participaron 19 ministerios, 15 de ellos con acciones directas junto a los TC, que componen su Comité Gestor Nacional. ${ }^{21}$ Estos son: Desarrollo Agrario-Incra, Desarrollo Social, Salud, Educación, Integración Nacional, Trabajo y Empleo, Medio Ambiente, Ciudades, Minas y Energía, Secretaría de Políticas para las Mujeres, Secretaría de Promoción de la Igualdad Racial, Secretaría de Agricultura y Pesca, Justicia-Funai, Agricultura, Ganadería y Abastecimiento, Cultura, Secretaría General, Planeación, Secretaría de Relaciones Institucionales, Casa Civil.

Así se observa una innovación importante en relación con los TR. En el ámbito del gobierno federal, se constituye un arreglo horizontal para articular las diferentes acciones. A su vez, con la creación de los comités de articulación estatales, que son los intermediarios en las relaciones entre el Comité Gestor Nacional y los colegiados territoriales, se pretende fortalecer la coordinación vertical entre las diferentes esferas de gobierno en la federación.

Además de esa articulación vertical, el Comité de Articulación Estatal coordina las acciones entre los representantes de los municipios miembros de los Territorios, así como los diversos órganos de los gobiernos estatal y federal con actuación en los estados. De esa forma, dicho Comité, de carácter consultivo y propositivo, tiene las siguientes tareas: apoyar la organización y movilización de los colegiados, fomentar la articulación e

\footnotetext{
${ }^{20}$ Organizaciones tradicionales constituidas por descendientes de esclavos.

${ }^{21}$ El Comité Gestor Nacional lo componen los secretarios ejecutivos o secretarios nacionales de todos los Ministerios que participan en el Programa.
} 
integración de las diversas políticas públicas en los territorios, acompañar la ejecución del Programa, auxiliar en la divulgación del mismo, y presentar sugerencias de acciones y de nuevos territorios.

Otra exigencia que facilita la articulación horizontal, ahora en el ámbito del territorio, es constituir colegiados territoriales con representantes de las tres esferas de gobierno y la sociedad civil local, con una composición paritaria bajo una coordinación ejecutiva. De esta manera, esos colegiados pasan a tener una composición ampliada en relación con los colegiados de los TR.

A pesar de esa ampliación, no se puede esperar una simplificación en la gestión local del Programa. La presencia de miembros de diferentes esferas de poder y de segmentos sociales, por sí sola ya implica dificultades para obtener consenso. Más difícil aún será el ejercicio de la gestión de los colegiados en función de la ampliación de las acciones que se les asignen. Desafío que requiere ser superado.

El gobierno federal definió, al crear los TC, 136 acciones organizadas en tres ejes estructurales: apoyo a las actividades productivas, ciudadanía y derecho e infraestructura. Además de siete temas: organización sustentable de la producción; acciones dirigidas a la estructura agraria; educación y cultura; derechos y desarrollo social; salud, saneamiento y acceso al agua; apoyo a la gestión territorial, e infraestructura.

De esas 135 acciones, 56 están dirigidas a apoyar las actividades productivas, 51 a las acciones de ciudadanía y acceso a derechos y 28 se planearon para mejorar la infraestructura. Por tanto, los TC, por su concepción y manejo, difieren de otros programas de enfoque territorial porque no se limitan a enfrentar problemas específicos con acciones dirigidas y articular diferentes acciones para promover el desarrollo.

En cuanto a los recursos previstos, se puede observar un incremento notable si se le compara con lo que se asignó a los Territorios Rurales. El presupuesto asignado a los tres ejes, en 2008, fue de 11.3 billones de reales. Así queda claro, tras algunos años de funcionamiento de los TR, que el gobierno federal reconoce las dificultades para fomentar un proceso de desarrollo endógeno a partir de las fuerzas económicas y sociales locales, y se amplía la gestión del Estado para que se alcancen los objetivos trazados.

En 2008, el Programa tc consiguió ejecutar 9.9 billones de reales de los 11.3 previstos, dividido en 175 acciones agrupadas en siete ejes: derechos y desarrollo social; organización sustentable de la producción; salud, tratamiento de aguas servidas y acceso a agua potable; educación y cultura; infraestructura; apoyo a la gestión territorial, y acciones referentes a la distribución de la propiedad de la tierra. 


\section{Cuadro 1 \\ Presupuesto de los TC en 2008 (en reales)}

\begin{tabular}{lrr}
\hline Derechos y desarrollo social & $4^{\prime} 974,768,837.19$ & $50.04 \%$ \\
Organización sustentable de la producción & $1^{\prime} 654,239,821.27$ & $16.64 \%$ \\
$\begin{array}{l}\text { Salud, tratamiento de aguas servidas y } \\
\text { acceso a agua potable }\end{array}$ & $1^{\prime} 487,533,230.76$ & $14.96 \%$ \\
Infraestructura en educación y cultura & $498,152,416.36$ & $5.01 \%$ \\
Infraestructura & 1 '129,853,780.27 & $11.37 \%$ \\
Apoyo a la gestión territorial & $18,104,857.94$ & $0.18 \%$ \\
$\begin{array}{l}\text { Acciones para distribución de la propiedad } \\
\text { de la tierra }\end{array}$ & $178,645,969.53$ & $1.80 \%$ \\
Total & 9 '941,298,913.32 & $100 \%$ \\
\hline
\end{tabular}

Fuente: MDA, 2010.

Como se constata en el cuadro 1, los recursos se concentraron en el eje de derechos y desarrollo social. En este tema, las acciones del Programa Bolsa Familia fueron las que recibieron más recursos: 26\% del presupuesto total destinado a los TC en 2008. Otras acciones de carácter asistencial, como el beneficio de prestación continuada de la asistencia social para la tercera edad y discapacitados, ${ }^{22}$ recibió $23 \%$ del total del presupuesto. Por tanto, como se puede deducir, esas dos acciones representan 49\% del presupuesto total del Programa.

En consecuencia, se puede cuestionar cuál es la capacidad de los TC para promover un proceso de desarrollo territorial dinamizador a partir de esos gastos. Esto se puede responder de manera parcial al observar que en las regiones donde el nivel de subdesarrollo es mayor, como en el Norte y el Nordeste, son precisamente la ejecución de programas sociales los que sobresalen en las inversiones del Estado, lo que revela su carácter concentrador de territorios deprimidos. A su vez, en la región donde los TC tienen un carácter relativamente más desarrollado, como es el caso de la región Sur, los recursos para la organización sustentable de la producción, dirigido a inversiones productivas, fue el rubro con mayor participación del presupuesto (50\%) (cuadro 2).

Por tanto, de acuerdo con datos de 2008, se constata que cuanto menos desarrollada es la región (Norte y Nordeste), mayores son los gastos presupuestados en programas compensatorios, principalmente con recursos concentrados en las acciones de Bolsa Familia y Beneficio de Prestación

\footnotetext{
${ }^{22}$ Este beneficio se destina a los ciudadanos en dichas situaciones que no reciben algún beneficio de pensión o jubilación y que declaren un ingreso per cápita inferior a un cuarto del salario mínimo de referencia. Ya que se trata de un beneficio de asistencia social, no se considera una pensión o jubilación.
} 


\section{Cuadro 2}

\section{Distribución del presupuesto TC en 2008 por región (porcentajes)}

\begin{tabular}{lccccc}
\hline & Sur & Sudeste & Centro-Oeste & Norte & Nordeste \\
\hline $\begin{array}{l}\text { Derechos y desarrollo } \\
\text { social }\end{array}$ & 31 & 44 & 50 & 54 & 53 \\
$\begin{array}{l}\text { Organización susten- } \\
\text { table de la producción }\end{array}$ & 50 & 20 & 18 & 12 & 13 \\
$\begin{array}{l}\text { Salud, tratamiento de } \\
\text { aguas servidas y acceso }\end{array}$ & 7 & 16 & 9 & 14 & 18 \\
$\begin{array}{l}\text { a agua potable } \\
\begin{array}{l}\text { Infraestructura en } \\
\text { educación y cultura }\end{array}\end{array}$ & 2 & 5 & 6 & 3 & 6 \\
$\begin{array}{l}\text { Infraestructura } \\
\text { Apoyo a la gestión }\end{array}$ & 9 & 11 & 11 & 16 & 10 \\
territorial & 0 & 0 & 0 & 0 & 0 \\
$\begin{array}{l}\text { Acciones para distribu- } \\
\text { ción de la propiedad } \\
\text { de la tierra }\end{array}$ & 1 & 3 & 6 & 2 & 1 \\
\hline
\end{tabular}

Fuente: MDA, 2010.

Continuada de la Asistencia Social para la tercera edad y discapacitados. Es posible concluir que en aquellas regiones aún se está lejos de superar una situación de pobreza, con mayor calificación para introducir y generar proyectos innovadores capaces de dinamizar la economía territorial. Así se observan, particularmente en las regiones donde predominan los territorios deprimidos, dificultades para las trayectorias virtuosas por medio de iniciativas autónomas y endógenas, que requieren mayor intervención pública del Estado.

\section{Potencialidades y límites de las territorialidades rurales}

En América Latina, las políticas de desarrollo que utilizan el enfoque territorial han sido adoptadas por recomendación de las agencias multilaterales y por iniciativa de los gobiernos nacionales como una forma de reducir las desigualdades. No obstante que estas recomendaciones se dan desde las esferas altas, esas estrategias han encontrando respaldo en los movimientos sociales locales, que reivindican mayor participación en la formulación y gestión de las políticas públicas. Así, se construye un aparente consenso en torno del desarrollo territorial.

En todas esas políticas se parte del principio de que el desarrollo de un territorio depende, en gran medida, de la organización y del pacto de su 
sociedad en torno a objetivos comunes. De esa manera, el llamado capital social sería la piedra angular en la búsqueda del desarrollo.

Como vimos, en Brasil esas políticas comenzaron a recibir atención en la década de 1980. En un contexto de crisis económica surgieron experiencias que buscaban respuestas autónomas para desarrollar los espacios locales. La victoria de la sociedad civil organizada que ha luchado por mayor participación en la gestión pública (en los consejos, presupuesto participativo), generó un proceso de radicalización de la democracia a partir de experiencias locales. Así, en oposición al régimen militar - principalmente por la falta de libertad política-, se fueron formando militantes que encontraron, en las visiones apologéticas del desarrollo local, la posibilidad de tomar el futuro en sus manos. Buscaban espacios para construir un modelo de desarrollo que negaba las formulaciones centradas en el modelo top-down de planeación, que no consideraba las opiniones de la sociedad local con respecto a los proyectos formulados por el gobierno central.

Para reforzar ese movimiento, en la corriente del llamado Consenso de Washington -tanto en Brasil como en otros países de América Latina- la década de 1990 estuvo marcada por un intenso proceso de desregulación de la economía. Así se siguió la tendencia neoliberal que se hizo hegemónica mundialmente, y que llevó a reducir la participación del Estado en la economía. La hegemonía neoliberal, validada por las agencias multilaterales, en particular el Banco Mundial y el Fondo Monetario Internacional, recomendó a los países en desarrollo el control de sus cuentas públicas para generar un superávit primario como forma de resolver el endeudamiento público. En ese sentido, aquellas instituciones también recomendaban el desarrollo local con la inducción, por parte de los gobiernos nacionales, de arreglos socioproductivos locales que de manera autónoma y endógena deberían buscar la chispa que detonara sus procesos de desarrollo. De esta manera el Estado dejaba de mantener las acciones intervencionistas que lo caracterizaron durante el periodo de hegemonía keynesiana.

Sin embargo, por distintas razones esas recomendaciones se incluyeron en las aspiraciones de los militantes del localismo, que anhelaban apartar a los gobiernos centrales autoritarios de las discusiones en torno al papel del Estado, pues crearon un aparente consenso alrededor del tema del desarrollo local, toda vez que ambos -agencias multilaterales y militantes localistas- mostraron las posibilidades para construir un modelo de desarrollo local autónomo y endógeno. En el caso de las agencias multilaterales, en función de esa menor intervención del Estado, la estrategia buscaba reducir los gastos públicos y generar superávits primarios, fundamentales para el equilibrio de las cuentas públicas que, en el caso de 
los países en desarrollo, sería fundamental para pagar sus deudas (Bм, 1999, 2000, 2001).

Ese consenso creado en torno al localismo, como destaca Brandão (2007), ha generado un verdadero pensamiento único, cuyas propuestas de acciones políticas de creación de arreglos socioproductivos reciben amplio respaldo, siempre desde una perspectiva endógena del desarrollo. En ese sentido, se recomienda adoptar nuevas estructuras de gobernanza y replicar esas buenas prácticas de otras localidades, ignorando particularidades espaciales y temporales. Por tanto, lo que es necesario indagar son las condiciones y perspectivas concretas para el desarrollo territorial-local en el proceso de transformación económica de la globalización. Un proceso que, como sustenta Batista, no nos puede paralizar, pues "La idea de que existe un proceso 'globalizante' en curso -idea que al mismo tiempo fascina y asusta- tiene el efecto práctico de paralizar las iniciativas nacionales y de desmovilizar las resistencias a los grandes intereses económicos-financieros que operan en escala internacional" (Batista, 2001: 45).

En ese sentido, la cuestión que se debe responder es: ¿cómo cada territorio puede y debe moverse en un proceso abrumador de cambios globales, que penetra e influye en todos los espacios, y cómo las políticas de desarrollo territorial pueden contribuir en ese desafío?

A pesar de la uniformización de las políticas públicas para los territorios, hay que observar que los resultados no siempre son los esperados. El éxito o fracaso de esas políticas, para muchos, depende en gran medida de las comunidades donde se están implementando, en relación directa con la capacidad de cooperación de la sociedad en torno de un proyecto colectivo. $^{23}$

No obstante, se debe coincidir con algunas críticas contundentes a la insuficiencia y límites de las estrategias de desarrollo territorial. Esa reticencia parte del principio de que la simple constitución de un arreglo socioproductivo no es capaz de liberar las sinergias locales para que el desarrollo se dé de manera autónoma y endógena, en particular en el caso de los territorios rurales deprimidos donde se debe reconocer la necesidad de infraestructura básica, capacitación y financiamiento en una realidad en la que sólo desde el Estado es posible asumir esas deficiencias.

Evidentemente pobreza no es sinónimo de incapacidad de organización social. Pero cuando analizamos las condiciones socioeconómicas en que se encuentran nuestros territorios deprimidos, se amplía el escepticismo en cuanto al éxito de las políticas de desarrollo territorial.

${ }^{23}$ Abramovay (2007), con base en Fligstein (2003), destaca la importancia de la cooperación. 
Para estimar el grado de desarrollo rural, Kageyama $(2004)^{24}$ sugirió la construcción de un índice de desarrollo rural (IDR) tomando como base la media aritmética simple de los siguientes índices: el de población (Ipop), el de bienestar social (Ibes), el de desarrollo económico (IDE) y el de medio ambiente (IMA). A partir de la construcción de ese índice síntesis, la autora lo aplicó a la realidad del estado de São Paulo y clasificó los resultados obtenidos en alto, medio y bajo. Los resultados para dicho estado, cuyo dinamismo económico y social es elevado en la realidad brasileña, señalaron que $16.7 \%$ de los municipios tienen un IDR bajo. Por su parte, Correa y Silva (2007), aplicando la misma metodología en las regiones Nordeste y Sur de Brasil, constataron que $75 \%$ de los municipios nordestinos presentan IDR muy bajos en comparación con la clasificación realizada para la región Sur.

Otro aspecto alarmante de la realidad latinoamericana, y causante de gran escepticismo sobre las posibilidades de alcanzar cohesión social para construir un proyecto consensuado de desarrollo territorial, se refiere al problema del hambre. De acuerdo con la FAO (2007), alrededor de 53 millones de latinoamericanos no se alimentan de manera suficiente. De ellos, se estima que aproximadamente nueve millones son niños que padecen desnutrición crónica. En el mismo sentido, de acuerdo con datos de la CEPAL (2005), 58\% de la población rural latinoamericana vive bajo la línea de pobreza y $34 \%$ en situación de indigencia.

Además de ello, se deben reconocer las críticas de Brandão (2003) que señala una gran ignorancia en muchos de los aspectos sobre este tema, principalmente cuando no se considera el ambiente macroeconómico, se minimizan los conflictos políticos locales, no se toma en cuenta de forma suficiente la estructura de clases sociales; se minimizan el papel del espacio y de las políticas nacionales, y no se consideran la historia y la inserción en el orden capitalista mundial.

\footnotetext{
${ }^{24}$ Esta autora propuso componer un índice de desarrollo rural a partir de la media aritmética simple de cuatro de otros indicadores: el índice de población (Ipop), el índice de bienestar social (Ibes), el índice de desarrollo económico (IDE) y el índice de medio ambiente (IMA). Los componentes de Ipop buscan medir el dinamismo poblacional que debería favorecer el desarrollo rural. "En líneas generales, cuanto mayor es la densidad demográfica, menor el aislamiento de las áreas rurales y mayores las oportunidades de establecimiento de redes sociales; cuanto mayor la población rural y su crecimiento en la década, mayor la capacidad del área rural de retener población; cuanto mayor la proporción de personas que vienen de otros municipios, mayor la capacidad de atracción que aquel municipio ejerce en la región" (Kageyama, 2004: 9). El Ibes, por su parte, se refiere apenas a la situación de bienestar en los domicilios rurales, con base en dos indicadores de equipamientos habitacionales (sanitario y teléfono) y dos indicadores de educación. El iDE “representa el 'núcleo duro' del desarrollo, por contener dos indicadores tradicionales a los que generalmente se reduce el concepto de desarrollo económico, la renta y la productividad” (Kageyama, 2004: 10). Por último, el indicador de ausencia de monocultivos se combinó con el indicador de conservación de suelos (media aritmética), generando el IMA para cada municipio.
} 
$\mathrm{Al}$ revisar las posibilidades de uso del enfoque territorial en las políticas de desarrollo rural no basta, por tanto, hacer apología del localismo, pues para los actores sociales que son parte de los innumerables arreglos socioproductivos que se distribuyen en el país, la cuestión se trata de una lucha por conseguir la inclusión social, política y económica con miras al desarrollo de sus localidades-territorios.

Por otro lado, es necesario aceptar los argumentos de quienes reconocen que la globalización destruye los mercados locales, pero también abre enormes posibilidades para la inserción en mercados globales. Evidentemente eso requiere calificación, organización logística, tecnológica y jamás puede ser una conquista individual, pues requiere entrar en una escala superior. Es decir, son necesarios proyectos colectivos, construidos con base en un sentimiento de pertenencia, ${ }^{25}$ participación, superación de los obstáculos políticos que dificultan la construcción de un pacto territorial, es decir, requiere una concertación con miras a buscar una suma diferente de cero. Lo que no significa que todos ganan lo mismo al participar, pero que todos ganan. Tampoco que los conflictos sociales intra e interclases se superen, pero que los conflictos se mantienen cerrados, en una acción estratégica concertada orientada al desarrollo territorial-local.

Por tanto, a nuestro entender, detrás de todo ese debate queda la siguiente pregunta a ser respondida: ¿cómo hacer posible la inclusión en los mercados de productos y servicios de determinadas localidades (territorios) deprimidas sin una fuerte presencia del Estado?

En ese contexto, las propuestas de desarrollo territorial se pueden comprender a partir de que se conciba con una perspectiva integradora, articulada en múltiples escalas, que puede ir desde lo local-comunitarioterritorial a lo global, incluso permitiendo su superposición y discontinuidad espacial, pero conectados y articulados entre sí. Es decir, estimamos necesaria una lectura integradora del espacio social, poco común pero que es necesaria para "una visión de territorio a partir de la concepción del espacio como un híbrido (entre sociedad y naturaleza, entre política, economía y cultura, y entre materialidad y idealidad), en una compleja interacción tiempo-espacio" (Haesbaert, 2006: 79), que tenga en cuenta no sólo las fuerzas endógenas, "sino también factores que son 'exógenos' a la localidad". Es decir, es necesario considerar jerarquías, poder, clases sociales, macroeconomía, entre otros factores muchas veces desdeñados (Brandão, 2007: 30).

Definidos de esa forma, los arreglos socioproductivos territoriales, tanto los resultantes de políticas públicas como los de constitución autó-

\footnotetext{
${ }^{25}$ Un sentimiento de pertenencia es más importante mientras más incluidos se sientan los individuos en los proyectos que se llevan a cabo en el territorio.
} 
noma y privada, pueden contribuir para dar mayor dinamismo a los territorios rurales.

\section{Bibliografía}

Abramovay, Ricardo (2003), O futuro das regióes rurais, Ufrgs, Porto Alegre.

Abramovay, Ricardo (2007), "Para uma teoria dos estudos territoriais", en Antonio César Ortega y Filho Niemeyer Almeida (coords.), Desenvolvimento territorial, segurança alimentar e economia solidária, Alínea, Campinas, pp. 19-37.

Amaral-Filho, Jair (2001), "A endogeneização no desenvolvimento econômico regional e local”, Planejamento e Políticas Públicas, 23, IPEA, Brasilia, pp. 261-286.

Batista, P. N. (2001), A economia como ela é..., Boitempo, São Paulo.

Bм (Banco Mundial) (1999), World development report 1999/2000: entering the 21st century-the changing development landscape, BM, Washington.

Bм (Banco Mundial) (2000), World development report 2000-2001: Attacking Poverty, BM, Washington.

вм (Banco Mundial) (2001), Rural development strategy and action plan for the Latin America and Caribbean region, vol. 1, BM, Nueva York.

Brandão, Carlos Antonio (2003), A dimensão espacial do desenvolvimento: uma agenda para os estudos regionais e urbanos, IE-Unicamp, Campinas.

Brandão, Carlos Antonio (2007), Território \& Desenvolvimento. As múltiplas escalas entre o local e global, Unicamp, Campinas.

Brasil (2003), Referências para o desenvolvimento territorial sustentável, MDA, Brasilia, <http://www.nead.gov.br>, 15 de abril de 2009.

Campanhola, Clayton y José Graziano da Silva (2000), "Desenvolvimento local e democratização dos espaços rurais. Brasília", Cadernos de Difusão de Tecnologia, 17 (1), Embrapa, Brasilia, pp. 11-40. 
Cassiolato, José Eduardo y Marina Szapiro (2003), "Uma caracterização de arranjos produtivos locais de micro e pequenas empresas", en Helena Maria Martins Lastres, José Eduardo Cassiolato y Maria Lucia Maciel (coords.), Pequena empresa: cooperação e desenvolvimento local, Relume Dumará-IE-UfRJ, Río de Janeiro, pp. 21-34.

Cepal (Comisión Económica para América Latina y el Caribe) (2005), Panorama social de América Latina 2005, Santiago, CePAL.

Condraf (Consejo Nacional de Desarrollo Rural Sostenible) (2003), "Referências para um Programa territorial de desenvolvimento rural sustentável”, texto para discusión, 4, Condraf-NEAD, Brasilia.

Correa, Vanessa Petrelli, Fernanda Faria-Silva y Henrique Dantas-Neder (2007), "Índice de desenvolvimento rural e políticas públicas. Análise das liberaçóes do Pronaf nas regiōes Nordeste e Sul do Brasil", en Antonio César Ortega (org.), Território, politicas públicas e estratégias de desenvolvimento, Alínea, Campinas, pp. 19-144.

Dagnino, Evelina (1994), "Os movimentos sociais e a emergência de uma nova noção de cidadania”, en Evelina Dagnino (org.), Os anos 90: política e sociedade no Brasil, Brasiliense, São Paulo, pp. 103-115.

Dagnino, Evelina (2002), "Sociedade civil e espaços públicos no Brasil”, en Evelina Dagnino (org.), Sociedade civil e espaços públicos no Brasil, Paz e Terra, São Paulo, pp. 9-15.

FAO (Organización de las Naciones Unidas para la Alimentación y la Agricultura) (2007), Hambre y cohesión social. Cómo revertir la relación entre inequidad y desnutrición en América Latina y el Caribe, FAO-CEPAL-PMA, Santiago, <http://www.rlc.fao.org/iniciativa/librocs.htm>, 15 de abril de 2009.

Favareto, Arilson (2007), Paradigmas do desenvolvimento rural em questão, Iglu-Fapesp, São Paulo.

Finot, Ivan (2005), "Descentralización, transferencias territoriales y desarrollo local", Revista de la CEPAL, 86, CEPAL, Santiago, pp. 29-46.

Fiori, José Luiz (1995), "O federalismo diante do desafio da globalização", en Rui de Brito Álvares-Affonso y Pedro Luiz Barros-Silva (orgs.), 
A federação em perspectiva: ensaios selecionados, Fundap, São Paulo, pp. 19-23.

Fligstein, Neil (2003), "O mercado enquanto política. Uma abordagem político-cultural às instituições de mercado", en José Peixoto y Rafael Marques (coords.), A nova sociología económica, Celta, Oeiras, Portugal, pp. 195-227.

Franca, Luiz Penna (2003), Consad, Formação de Consórcios de Segurança Alimentar e Desenvolvimento Local, IBAM-DES-NEL, Río de Janeiro.

Graziano-da Silva, José (1999), Novo rural brasileiro, Unicamp, Campinas.

Graziano-da Silva, José (2001), "El desarrollo local en contextos de globalización. Una reflexión desde la experiencia del mundo rural brasileño", Informe Socioeconómico de la Agricultura Española, Ministerio de Agricultura, Pesca y Alimentación, Madrid.

Haesbaert, Rogério (2006), O Mito da desterritorialização. Do "fim dos territórios" à multiterritorialidade, Bertrand, Río de Janeiro.

IBAM (Instituto Brasileño de Administración Municipal) (2003), Guia do Consas: consórcio de segurança alimentar e desenvolvimento local, IBAM-DES-NEL, Río de Janeiro.

Kageyama, Angela (2004), "Desenvolvimento rural: conceito e um exemplo de medida", Anais do XLIII Congresso Nacional da Sociedade Brasileira de Economia e Sociologia Rural, Cuiabá, Brasil, 25-28 de julio.

MDA (Ministério do Desenvolvimento Agrário) (2010), Sistema de Informaçōes Territoriais do Ministério do Desenvolvimento Agrário, MDA, Brasilia.

Mohar, Alejandro (2008), "Políticas de desarrollo y ordenamiento territorial", Seminario de Expertos Biocombustibles: oportunidades, desafíos y políticas públicas, 5-7 de marzo,Fodepal, Bogotá.

Moyano-Estrada, Eduardo (1999), "El concepto de capital social y su utilidad para el análisis de las dinámicas del desarrollo", Revista Economia Ensaios, 13-14 (1-2), Edufu, Uberlandia, pp. 3-39. 
Ortega, Antonio César (2008), Territórios deprimidos. Os desafios das políticas de desenvolvimento territorial rural, Alínea, Campinas.

PFZ (Programa Fome Zero) (2003), “Documento preliminar para discussão interna no Consea”, PFZ, Brasilia.

Reis, José (2002), “A globalização como metáfora da perplexidade? Os processos geo-económicos e o 'simples' funcionamento dos sistemas complexos", en Boaventura Sousa-Santos (coord.), A globalização e as ciências sociais, Cortez, São Paulo, pp. 109-134.

Schneider, Sergio e Iván Gerardo Peyré-Tartaruga (2006), “Territorio y enfoque territorial: de las reformas cognitivas a los aportes aplicados al análisis de los procesos sociales rurales", en Guillermo Mabel-Manzal, Guillermo Neiman y Mario Lattuada (orgs.), Desarrollo rural, organizaciones, instituciones y territorios, vol. 1, Ciccus, Buenos Aires, pp. 71-102.

Sepúlveda, Sergio, Adrián Rodríguez, Rafael Echeverri y Melania Portilla (2003), El enfoque territorial del desarrollo rural, IICA, San José.

Veiga, José Eli da (2002), Cidades imaginárias. O Brasil é menos urbano do que se calcula, Autores Associados, Campinas.

Recibido: 7 de agosto de 2009. Reenviado: 7 de noviembre de 2010. Aceptado: 20 de enero de 2011.

Antonio César Ortega. Es doctor en ciencias económicas y empresariales por la Universidad de Córdoba (ESP); hizo un posdoctorado en economía en la Universidade Estadual de Campinas, Brasil. Es profesor del Instituto de Economía de la Universidade Federal de Uberlândia. Sus líneas de investigación son: desarrollo rural, desarrollo territorial, seguridad alimentaria y representación de intereses. Entre sus últimas publicaciones sobresalen: Territórios deprimidos. Os desafios das políticas de desenvolvimento territorial rural, Alínea, Campinas (2008); Agronegócio e representação de interesses rurais no Brasil, Edufu, Uberlândia (2008); "Café do cerrado. Certificação de origem e desenvolvimento territorial rural", en Luís Moreno, Maria Mercedes Sánchez y Orlando Simóes (orgs.), Cultura, inovação e território: o agroalimentar e o rural, vol. 1, SPER, Lisboa, pp. 205-214 (2009). 